\title{
Effect of photodynamic therapy combined with Celecoxib on expression of cyclooxygenase-2 protein in HeLa cells
}

\author{
YUANFU MAO, LISHUANG WANG, CHEN XU and SHIYU HAN
}

\author{
Department of Gynecology and Obstetrics, The Fourth Affiliated Hospital of Harbin Medical University, \\ Harbin, Heilongjiang 150001, P.R. China
}

Received November 3, 2016; Accepted November 2, 2017

DOI: $10.3892 / \mathrm{ol} .2018 .8163$

\begin{abstract}
The present study assessed the effect of photodynamic therapy (PDT) combined with Celecoxib (Cel) on cervical cancer HeLa cells. An MTT assay was performed to detect the inhibitory effects of Cel with different concentrations $(10,50,100,150,200,250$ and $300 \mu \mathrm{g} / \mathrm{ml})$ on the proliferation of HeLa cells. Subsequently, HeLa cells were divided into control group (group $\mathrm{H}$ ), $50 \mathrm{~g} / \mathrm{ml}$ Celecoxib group (group C), PDT group (group P), $50 \mathrm{~g} / \mathrm{ml} \mathrm{Cel} \mathrm{+} \mathrm{PDT} \mathrm{group}$ (group $\mathrm{P}+\mathrm{C}$ ) and western blotting and immunohistochemistry were performed to detect the expression of cyclooxygenase-2 (COX-2) protein in the different groups. Cel inhibited HeLa cells proliferation $24 \mathrm{~h}$ following administration, among which $200 \mu \mathrm{g} / \mathrm{ml}$ induced a $50 \%$ inhibition rate; the relative expression level of $\mathrm{COX}-2$ protein in group $\mathrm{P}+\mathrm{C}$ was significantly decreased compared with that in either group $\mathrm{C}$ or group $\mathrm{P}(\mathrm{P}<0.05)$. Cel inhibited the proliferation of human cervical cancer cells in a concentration-dependent manner, and combined PDT therapy may improve treatment outcomes.
\end{abstract}

\section{Introduction}

Cervical cancer (CC) is a common malignancy in females, with the second-highest mortality rate of cancer in females worldwide $(1,2)$ and it affects mostly women of reproductive age; $14.0 \%$ of patients diagnosed with cervical cancer are between 20 and 34 and $25.9 \%$ between 35 and 44 years of age (3). Traditional treatment methods primarily include surgery, chemotherapy and radiotherapy and are supplemented by comprehensive therapies, including immunotherapy, biological therapy (targeting dendritic cells and cytokine induced killer cells) and genetic therapy (4-6). The presence of an isozyme of

Correspondence to: Dr Lishuang Wang, Department of Gynecology and Obstetrics, The Fourth Affiliated Hospital of Harbin Medical University, 37 Yiyuan Street Nangang, Harbin, Heilongjiang 150001, P.R. China

E-mail: yfwdoc@126.com

Key words: photodynamic therapy, Celecoxib, cyclooxygenase-2, cervical cancer cyclooxygenase (COX), cyclooxygenase 2 (COX-2), has been confirmed in a variety of human tumor tissues and cells (7). COX-2 inhibitors may participate in the occurrence and development of tumors through enhancing tumor nourishing angiogenesis, inhibiting immune surveillance, promoting cell proliferation, enhancing tumor invasion/metastasis or inhibiting apoptosis and therefore they are associated with the prognosis of patients with tumors (8). Studies have demonstrated that COX-2 is not expressed in normal cervical tissues, but that its expression in CC is significantly increased (9). Consequently, COX-2 inhibitors have become a focus of CC therapies (10).

Following clinical application, numerous studies have confirmed the efficacy of photodynamic therapy (PDT) in treating tumors $(11,12)$, but the mechanism of action remains unclear; at present, potential mechanisms include inducing apoptosis, activating in vivo antitumor immunity reactions and injuring tumor-associated vasculature (13). Almeida et al (14) hypothesized that PDT induces apoptosis primarily through 2 signal transduction pathways: The death receptor-mediated external and the mitochondria-mediated internal pathway. Zhou et al (15) suggested that PDT may also increase the concentration of $\mathrm{Ca}^{2+}$ in the cytoplasm, activate the metabolism of certain lipids, including phospholipase C, ceramide, phospholipase A2 and arachidonic acid, and induce apoptosis. COX-2 inhibitors and PDT may act on COX-2, the rate-limiting enzyme via which arachidonic acid synthesizes prostaglandins (PGs), thereby decreasing the synthesis of PGs and inhibiting the action of COX-2.

The present study examined selective COX-2 inhibitor Cel combined with PDT and their inhibitory functions against the expression and proliferation of COX-2 in HeLa cells, aiming to additionally explore the potential mechanisms through which the apoptosis of CC is induced and consequently providing a theoretical basis for the clinical applications of Cel and PDT. At present, the associations between PDT and selective COX-2 inhibitors in treating $\mathrm{CC}$ have not been described and studies concerning the effect of $\mathrm{Cel}$ and PDT on the expression and proliferation of COX-2 in HeLa cells have not been performed, to the best of our knowledge. The present study will provide novel ideas for the clinical prevention and treatment of $\mathrm{CC}$ and is therefore of important practical significance in improving the survival rates and decreasing the mortality rates of CC. With advances from previous studies and clinical studies, 
this combined therapy may have broad application prospects toward the prevention and treatment of early and advanced CC $(16,17)$.

\section{Materials and methods}

Cell lines and groups. HeLa cells (Obstetrics and Gynecology Department, the Fourth Affiliated Hospital of Harbin Medical University, Harbin, China) were co-cultured at room temperature with 50,100,150, 200, 250 and $300 \mu \mathrm{g} / \mathrm{ml} \mathrm{Cel} \mathrm{and} \mathrm{then}$ $5 \mathrm{mg} / \mathrm{ml}$ MTT in PBS was added for an additional $4 \mathrm{~h}$ incubation in room temperature prior to the measurement of optical density (OD) values at $492 \mathrm{~nm}$; the inhibition rate of COX-2 in the HeLa cells was calculated as: Inhibition rate $=(\mathrm{OD}$ of the negative control group-OD of the sample)/(OD of the negative control group-OD of the blank group) $\mathrm{x} 100 \%$.

The HeLa cells were divided into 4 groups according to different treatment options: Blank control (Hela, group $\mathrm{H}$ ); group Cel (group C, $50 \mu \mathrm{g} / \mathrm{ml}$ ); group PDT (group P); and group PDT + Cel [group P + C, $($ Cel $50 \mu \mathrm{g} / \mathrm{ml})]$.

PDT treatment. One DIOMED630 photodynamic laser treatment apparatus (Diomed Ltd., Hertfordshire, UK) was used based on Photofrine (American Cyanamid Company, New Jersey, USA) to spirally irradiate the culture plates for $25 \mathrm{sec}$, with the output power as $440 \mathrm{~nm}$ at the site $3 \mathrm{~cm}$ away from the light spot and the power density as $15 \mathrm{~mW} / \mathrm{cm}^{2}$; the cells were then cultured in Dulbecco's modified Eagle's medium (Thermo Fisher Scientific, Inc., Waltham, MA, USA) with $15 \%$ fetal bovine serum (Thermo Fisher Scientific, Inc.) at $37^{\circ} \mathrm{C}$ and $5 \% \mathrm{CO}_{2}$ for $24 \mathrm{~h}$.

Western blotting. The total proteins were extracted from Hela cells using lysis buffer (P0013; Beyotime Institute of Biotechnology, Haimen, China) (radioimmunoprecipitation assay: Phenylmethane sulfonyl fluoride $=100: 1)$ for $30 \mathrm{~min}$ at $4^{\circ} \mathrm{C}$ and then $25 \mu \mathrm{g}$ was separated using SDS-PAGE (10\% gel) and transferred to a polyvinylidene fluoride membrane. Then the membrane was blocked with $5 \%$ skimmed milk in Tris-buffered saline with 20\% Tween-20 for $2 \mathrm{~h}$. The dilution of COX-2 primary anti-mouse antibodies (cat. no. aa584-598; Cayman Chemical Company, Ann Arbor, MI, USA) was 1:200, incubated at $4^{\circ} \mathrm{C}$ overnight; that of the rabbit anti-mouse immunoglobulinG secondary antibodies (cat. no. A-11059; Thermo Fisher Scientific Inc.) was 1:5,000. The analysis of the bands was used to detect the expression of COX-2 with $\beta$-actin (cat. no. MAB8969; Bio-Techne, Minneapolis, MN, USA), diluted by deionized water (1:200), as a reference and the ratio of gray between COX- 2 and $\beta$-actin was defined as the relative expression of COX-2 by Quantity One (version 4.6.2; Bio-Rad Laboratories, Inc., Hercules, USA). The experiment was repeated $\geq 3$ times.

Immunohistochemical staining. COX-2 protein expression was detected by $5 \mathrm{mg} / \mathrm{ml} \mathrm{DAB}$ staining (room temperature for $4 \mathrm{~min}$ ) with $50 \mu$ l primary (1:50, aa584-598; Cayman Chemical Company) and $50 \mu 1$ biotin-labeled secondary antibodies (1:200, A-1,1059; Thermo Fisher Scientific, Inc.), which were both diluted with PBS contains $0.3 \%$ Triton $\mathrm{x}$-100. The positive cells displayed brownish yellow granules on the surface and cytoplasm. The expression grades of COX-2 were based on the ratio of positive cells among all the cells when calculated from 1,000 cells randomly from 10 high power fields: $<5 \%$, negative (-); 6-25\%, weakly positive (+); $26-50 \%$, positive (++); and $>51 \%$, strong positive $(+++)$ by light microscope (magnification, x400, Olympus Corporation, Tokyo, Japan).

Statistical analysis. SPSS v11.5 (SPSS, Inc., Chicago, IL, USA) was used for statistical analysis and two-way analysis of variance with Turkey's test as the post hoc test for western blot results and the $\chi^{2}$ test was applied to the immunohistochemical staining results. $\mathrm{P}<0.05$ was considered to indicate a statistically significant difference.

\section{Results}

Proliferation inhibition of COX-2. The OD values of HeLa cells at multiple concentrations of Cel were measured by MTT assay; subsequently, the cell survival curves were calculated with the OD value as the ordinate and the Cel concentration as the abscissa (Fig. 1A). The proliferation inhibition rate of COX-2 at different concentrations of $\mathrm{Cel}$ is demonstrated in Fig. 1B, which exhibited a dose-dependent trend. When the inhibition rate was $50 \%$, the Cel concentration was $200 \mu \mathrm{mol} / 1$. In group $\mathrm{C}$, microscopy revealed that the membrane and cytoplasm of the HeLa cells were initially stained brown, followed by membrane and nucleus shrinkage, cracking and gradual formation of cellular debris.

Expression of COX-2 protein. The expression of COX-2 protein was highest in group $\mathrm{H}$, while in PDT + Cel-treated HeLa cells it was significantly decreased $(\mathrm{P}<0.05)$ (Table I). From the western blot, there was no statistically significant difference between groups $\mathrm{C}$ and $\mathrm{H}(\mathrm{P}>0.05)$ (Table I) observed, but the comparison between groups $\mathrm{P}$ and $\mathrm{H}$ indicated a statistically significant difference $(\mathrm{P}<0.05)$ (Table I). Fig. 2 demonstrates the western blotting data and Fig. 3 presents the immunohistochemical staining results.

\section{Discussion}

COX-2 is the rate-limiting enzyme via which arachidonic acid synthesizes PGs (18) and, with the exception of red blood cells, all other body tissues possess the enzymes for the synthesis of prostaglandins (PGs). Platelets also have thromboxane A synthase 1 , which has been confirmed by an inhibition experiment (19). Phospholipids in the cell membrane are rich in arachidonic acid so when the cells are stimulated by external stimuli, including bradykinin, thrombin, antigen-antibody complexes or other pathological factors, a number of which have not yet been characterized, the phospholipase A2 in cell membrane will be activated, consequently hydrolyzing the phospholipids and releasing arachidonic acid, which may then synthesize PGs under a series of enzymes including COX-2 and PGs synthetase (20). In the majority of normal tissues, PG is not expressed; however, under the stimuli of factors such as cytokines, growth factors, oncogenes or tumor-promoting agents, it may be upregulated and associated with the occurrence and development of tumors (21). Previous study has identified that COX-2 is upregulated in a number 
Table I. Expression levels of COX-2 protein in different groups.

\begin{tabular}{lcccc}
\hline & \multicolumn{5}{c}{ Groups } \\
\cline { 2 - 5 } Expression & $\mathrm{H}$ & $\mathrm{C}$ & $\mathrm{P}$ & $\mathrm{P}+\mathrm{C}$ \\
\hline COX-2/ $\beta$-actin & $0.83 \pm 0.17$ & $0.73 \pm 0.15$ & $0.51 \pm 0.13^{\mathrm{a}}$ & $0.36 \pm 0.14^{\mathrm{a}-\mathrm{c}}$ \\
Positive rate of COX-2 & +++ & ++ & - & - \\
\hline
\end{tabular}

,$-<5 \% ;+, 6-25 \% ;++, 26-50 \% ;+++,>51 \%$; group $\mathrm{H}$, blank control group; group C, Cel group; group P, PDT group; group P + C, PDT + Cel group. PDT, photodynamic therapy; Cel, Celecoxib; COX-2, cyclooxygenase 2 . ${ }^{a} \mathrm{P}<0.05$ vs. group $\mathrm{H} ;{ }^{b} \mathrm{P}<0.05$ vs. group $\mathrm{C}$; ${ }^{\mathrm{P}}<0.05$ vs. group $\mathrm{P}$.
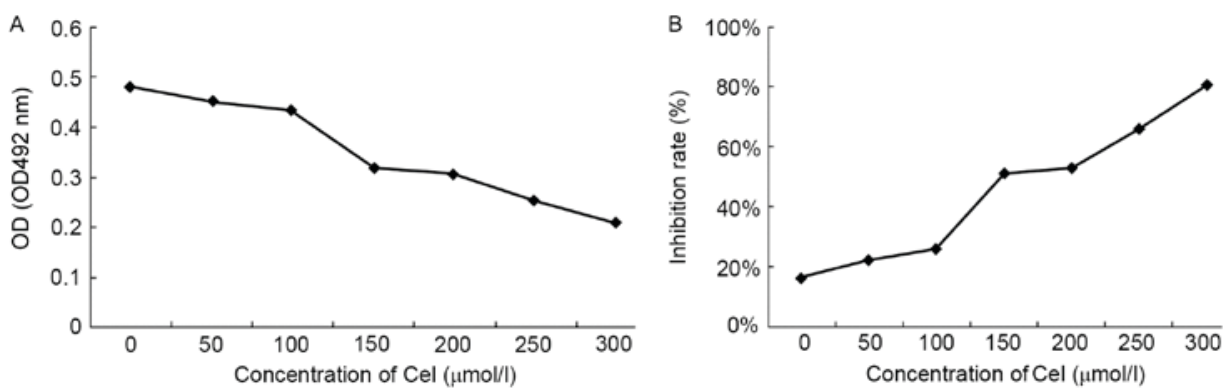

Figure 1. (A) Association between Cel concentration and OD of HeLa cells. (B) Inhibition rate of Cel against cervical cancer cells. OD, optical density; Cel, Celecoxib.

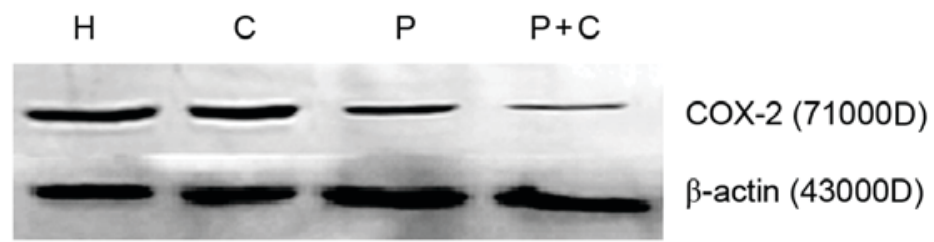

Figure 2. Expression levels of COX-2 protein in HeLa cells of different groups. COX-2, cyclooxygenase 2; PDT, photodynamic therapy; Cel, Celecoxib; group H, blank control; group C, Cel group; group P, PDT group; group P + C, PDT + Cel group.

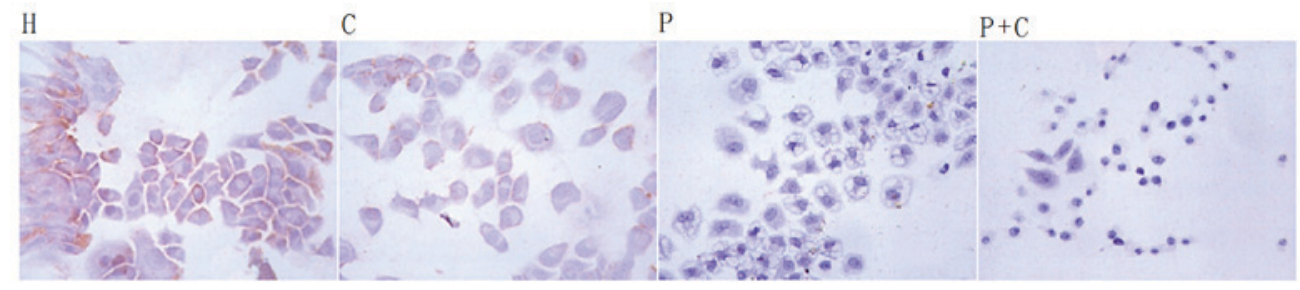

Figure 3. Immunohistochemical staining of cyclooxygenase 2 protein in different groups (magnification, $\mathrm{x} 40$ ). $\mathrm{H}$ for control group, $\mathrm{C}$ for $50 \mathrm{~g} / \mathrm{ml} \mathrm{Celecoxib}$ group, $\mathrm{P}$ for photodynamic therapy group, $\mathrm{P}+\mathrm{C}$ for $50 \mathrm{~g} / \mathrm{ml}$ Celecoxib + photodynamic therapy group.

of tumor tissues and is associated with tumorigenesis, malignant transformation, resistance or prognosis (22). It may participate in the occurrence and development of tumors via enhancing angiogenesis of neovascularization, inhibiting immune surveillance promoting cell proliferation, enhancing invasion/metastasis and inhibiting apoptosis (23). Chen et al (24) identified that COX-2 is not expressed in normal cervical tissues and is primarily expressed in CC cells and in the neovascular endothelial cells of $\mathrm{CC}$, so it may be presumed that it participates in the angiogenesis of $\mathrm{CC}$. Previous studies have also demonstrated that COX-2 is significantly associated with the pathological grading, cytology and lymph node metastasis of $\mathrm{CC}$, the expression rate of which is increased in adenocarcinoma compared with squamous carcinoma; COX-2 is highly expressed in well-differentiated tumors and it may be hypothesized that COX-2 serves functions in the early stages of CC (25), is associated with lymph node metastasis (26) and is associated with the occurrence and metastasis of CC (27). Gaffney et al (28) followed up patients with CC following radiotherapy and identified that the decrease of COX-2 level was the only factor to improve the survival rate: The 5-year overall survival rates in the patients with high and low COX-2 
expressions were 75 and $35 \%$, respectively, indicating that the upregulation of COX-2 may decrease the post-radiotherapy survival rate in patients with $\mathrm{CC}$.

Selective COX-2 inhibitors may specifically act on COX-2, thus decreasing the synthesis of PGs and inhibiting tumors (29). A previous study indicated that Cel pretreatment radiosensitizes HeLa cells via a mechanism dependent on downregulating COX-2 (30), indicating that long-term and regular application of selective COX-2 inhibitors contributes to improving the rate of apoptosis and the sensitivity of radiotherapy and chemotherapy, consequently increasing the 5-year survival rate. A previous study demonstrated that the selective COX-2 inhibitor NS398 may inhibit the growth of epithelial cells of ovarian cancer in a concentration- and time-dependent manner and that the cells with and without the expression of COX-2 exhibited a statistically significant difference in prognosis, which suggests that the inhibitory functions of NS398 against the growth of ovarian cancer cells were mediated through the inhibition of COX-2 expression, resulting in the decrease of $\mathrm{PG}$ synthesis rate and a facilitation of apoptosis in a time- and dose-dependent manner (30).

In the present study, the MTT assay revealed that the selective COX-2 inhibitor Cel may inhibit the proliferation of human CC HeLa cells and exhibit an association with Cel, consistent with a previous study (31).

The principle of PDT is that, subsequent to intravenous or intraperitoneal administration, the photosensitizer may be taken up by tumor tissues so that, when a laser with a suitable wavelength is introduced, the photochemical effects may be induced to kill tumor cells, which is effective toward chemotherapy- or radiation-resistant tumor cells. Colussi et al (32) applied the photosensitizer metal phthalocyanine to nude mice with human ovarian OVCAR3 carcinoma xenografts, and identified that the tumor tissues exhibited early apoptosis and the overexpression of cyclin-dependent kinase inhibitor 1 , but that the group without the PDT did not. Applying PDT to treat ovarian cancer incurs certain problems; as a small amount of photosensitizer is absorbed by intraperitoneal normal tissues and organs, large-area irradiation targeting the abdominal cavity will not only achieve effective irradiation against the tumor tissues and therefore affect treatment efficacy but may also damage normal peritoneal tissues and organs, causing intestinal perforation. Therefore, carrier systems such as liposomes or monoclonal antibodies are required so as to improve the selective accumulation of the photosensitizer (33). To assess the effect of Cel plus PDT on the expression of COX-2 protein in HeLa cells, western blotting and immunohistochemistry assays were used to examine the expression of COX-2, with Photofrine ${ }^{\circledR}$ as the photosensitizer. The results indicated that the expression of COX-2 protein in group $\mathrm{P}+\mathrm{C}$ was significantly decreased compared with that in the other 3 groups, which was improved compared with group $\mathrm{P}$ and group $\mathrm{C}$. The results of immunohistochemical analysis also supported the results obtained by western blotting, indicating that the selective COX-2 inhibitor Cel combined with PDT may exhibit inhibitory effects on the expression of COX-2 in HeLa cells, resulting in the downregulation of COX-2 protein. However, group $\mathrm{P}$ also exhibited inhibitory effects on the expression of COX-2 in HeLa cells, but the effects were decreased compared with those in group $\mathrm{P}+\mathrm{C}$; no statistically significant difference between groups $\mathrm{C}$ and $\mathrm{H}$ was observed and this may be due to the concentration selected or decreased duration of exposure, meaning that the protein was not significantly downregulated. This result is not contradictory to that obtained in the MTT assay, since Cel inhibited the HeLa cells in a concentration- and time-dependent model; the higher the concentration and the longer the duration of the treatment, the more marked the inhibitory effects against COX-2 appeared. The cells in group $\mathrm{P}+\mathrm{C}$ exhibited apoptotic bodies but no COX-2 expression according to the immunohistochemical analysis, indicating a possible pathway COX-2 inhibition, which may reduce the rate of PGs and promote apoptosis; however, other pro-apoptosis pathways should not be ruled out and this requires additional study.

The greatest obstacle of Cel plus PDT in current clinical applications is that the penetration distance of PDT is short, usually $<1 \mathrm{~cm}$, but the speed of promoting the apoptosis is fast. Since $\mathrm{Cel}$ is an oral drug, therefore it may only be used as a means of adjuvant therapy instead of a primary treatment, so as to help to improve the clinical prognosis of CC. For patients who are resistant to radiotherapy and chemotherapy, treatment sensitivity may be increased. Cel combined with PDT may be used as an early treatment of cervical intraepithelial neoplasia and as an adjuvant treatment for advanced $\mathrm{CC}$, which is crucial for improving the 5-year survival and quality of life of patients. Therefore, with ongoing basic studies and clinical trials, the combination of Cel and PDT may be expected to become a novel approach for the prevention of $\mathrm{CC}$.

\section{Acknowledgements}

The present study was supported by Science and Technology Projects of Department of Education of Heilongjiang (grant no. 12541519).

\section{References}

1. Liu X, Chen D, Liu J, Chu Z and Liu D: Blocking modification of eukaryotic initiation 5A2 antagonizes cervical carcinoma via inhibition of RhoA/Rock signal transduction pathway. Technol Cancer Res Treat 16: 630-638, 2016.

2. Thomakos N, Trachana SP, Davidovic-Grigoraki M and Rodolakis A: Less radical surgery for early-stage cervical cancer: To what extent do we justify it? Our belief. Taiwan J Obstet Gynecol 55: 495-498, 2016.

3. National Cancer Institute: SEER Data: Surveillance, epidemiology and end results program. http://seer.cancer. gov/statfacts/html/cervix.html. Accessed 16 January 2017.

4. Mallmann P and Mallmann C: Neoadjuvant and adjuvant chemotherapy of cervical cancer. Oncol Res Treat 39: 522-524, 2016.

5. Brucker SY and Ulrich UA: Surgical treatment of early-stage cervical cancer. Oncol Res Treat 39: 508-514, 2016.

6. Li H, Wu X and Cheng X: Advances in diagnosis and treatment of metastatic cervical cancer. J Gynecol Oncol 27: e43, 2016.

7. Zong M, Fan DD, Lin S, Song YP, Wang ZY, Ma XL, Qiu WH, Bai YH, Li L and Li S: Anti-cancer activity and potential mechanism of a novel aspirin derivative. Eur J Pharmacol 791: 137-146, 2016.

8. Montrose DC, Zhou XK, McNally EM, Sue E, Yantiss RK, Gross SS, Leve ND, Karoly ED, Suen CS, Ling L, et al: Celecoxib alters the intestinal microbiota and metabolome in association with reducing polyp burden. Cancer Prev Res (Phila) 9: 721-731, 2016.

9. Jawanjal P, Salhan S, Dhawan I, Das N, Aggarwal R, Tripathi R and Rath G: Augmented activity of cyclooxygenase-2 in tissue and serum of patients with cervical cancer. J Clin Lab Anal 30: 1198-1207, 2016 
10. Setiawati A and Setiawati A: Celecoxib, a COX-2 selective inhibitor, induces cell cycle arrest at the G2/M phase in HeLa cervical cancer cells. Asian Pac J Cancer Prev 17: 1655-1660, 2016.

11. Huang Z: A review of progress in clinical photodynamic therapy. Technol Cancer Res Treat 4: 283-293, 2005.

12. Dougherty TJ, Henderson BW, Schwartz S, Winkelman JW and Lipson RL: Historical Perspective in Photodynamic Therapy. In: Henderson BW and Dougherty TJ (eds). Maurice Dekker, New York, NY pp1-18, 1992.

13. Garg T, Jain NK, Rath G and Goyal AK: Nanotechnology-based photodynamic therapy: Concepts, advances and perspectives. Crit Rev Ther Drug Carrier Syst 32: 389-439, 2015.

14. Almeida RD, Manadas BJ, Carvalho AP and Duarte CB: Intracellular signaling mechanisms in photodynamic therapy. Biochim Biothys Acta 1704: 59-86, 2004.

15. Zhou Z, Yang H and Zhang Z: Role of calcium in phototoxicity of 2-butylamino-2-demethoxy-hypocrellin A to human gastric cancer MGC-803 cells. Biochim Biophys Acta 1593: 191-200, 2003.

16. Stern PL, van der Burg SH, Hampson IN, Broker TR, Fiander A, Lacey CJ, Kitchener HC and Einstein MH: Therapy of human papillomavirus-related disease. Vaccine 30 (Suppl 5): F71-F82, 2012.

17. Olivo M, Bhuvaneswari R, Lucky SS, Dendukuri N and Soo-Ping Thong P: Targeted therapy of cancer using photodynamic therapy in combination with multi-faceted anti-tumor modalities. Pharmaceuticals (Basel) 3: 1507-1529, 2010

18. Gariepy H, Zhao J and Levy D: Differential contribution of COX-1 and COX-2 derived prostanoids to cortical spreading depression-Evoked cerebral oligemia. J Cereb Blood Flow Metab 37: 1060-1068, 2016.

19. Son DJ, Akiba S, Hong JT, Yun YP, Hwang SY, Park YH and Lee SE: Piperine inhibits the activities of platelet cytosolic phospholipase A2 and thromboxane A2 synthase without affecting cyclooxygenase-1 activity: Different mechanisms of action are involved in the inhibition of platelet aggregation and macrophage inflammatory response. Nutrients 6: 3336-3352, 2014.

20. Akasaka $\mathrm{H}$ and Ruan $\mathrm{KH}$ : Identification of the two-phase mechanism of arachidonic acid regulating inflammatory prostaglandin E2 biosynthesis by targeting COX-2 and mPGES-1. Arch Biochem Biophys 603: 29-37, 2016.

21. Boutaud O, Sosa IR, Amin T, Oram D, Adler D, Hwang HS, Crews BC, Milne GL, Harris BK, Hoeksema M, et al: Inhibition of the biosynthesis of prostaglandin E2 by low dose aspirin Implications for adenocarcinoma metastasis. Cancer Prev Res (Phila) 9: 855-865, 2016.
22. Shigemasa K, Tian X, Gu L, Shiroyama Y, Nagai N and Ohama K: Expression of cyclooxygenase-2 and its relationship to 553 accumulation in ovarian adenocarcinomas. Int J Oncol 22: 99-105, 2003

23. Gawthorpe S, Brown JE, Arif M, Nightingale P, Nevill A and Carmichael AR: Heparanase and COX-2 expression as predictors of lymph node metastasis in large, high-grade breast tumors. Anticancer Res 34: 2797-2800, 2014.

24. Chen YJ, Wang LS, Wang PH, Lai CR, Yen MS, Ng HT and Yuan CC: High cyclooxygenase-2 expression in cervical adenocarcinomas. Gynecol Oncol 88: 379-385, 2003.

25. Zhou WQ, Sheng QY, Sheng YH, Hou WJ, Xu GX, Wu YM and Lu H: Expressions of survivin, P16(INK4a), COX-2 and Ki-67 in cervical cancer progression reveal the potential clinical application. Eur J Gynaecol Oncol 36: 62-68, 2015.

26. Liu H, Xiao J, Yang Y, Liu Y, Ma R, Li Y, Deng F and Zhang Y: COX-2 expression is correlated with VEGF-C, lymphangiogenesis and lymph node metastasis in human cervical cancer. Microvasc Res 82: 131-140, 2011.

27. Xia S, Zhao Y, Yu S and Zhang M: Activated PI3K/Akt/COX-2 pathway induces resistance to radiation in human cervical cancer HeLa cells. Cancer Biother Radiopharm 25: 317-323, 2010.

28. Gaffney DK, Holden J, Davis M, Zempolich K, Murphy KJ and Dodson M: Elevated cyclooxygenase-2 expression correlates with diminished survival in carcinoma of the cervix treated with radiotherapy. Int J Radiat Oncol Biol Phys 49: 1213-1217, 2001.

29. Sakonlaya D, Tapanadechopone P, Poomkokruk A and Charoenvilaisiri S: Do NSAIDs inhibit growth of precancerous cervical cells in vitro? J Med Assoc Thai 95 (Suppl 1): S65-S73, 2012.

30. Wang AH, Tian XY, Yu JJ, Mi JQ, Liu H and Wang RF: Celecoxib radiosensitizes the human cervical cancer HeLa cell line via a mechanism dependent on reduced cyclo-oxygenase-2 and vascular endothelial growth factor $\mathrm{C}$ expression. J Int Med Res 40: 56-66, 2012.

31. Sadeghi-Aliabadi H, Aliasgharluo M, Fattahi A, Mirian M and Ghannadian M: In vitro cytotoxic evaluation of some synthesized COX-2 inhibitor derivatives against a panel of human cancer cell lines. Res Pharm Sci 8: 298-303, 2013.

32. Colussi VC, Feyes DK, Mulvihill JW, Li YS, Kenney ME, Elmets CA, Oleinick NL and Mukhtar H: Phthalocyanine 4 (PC4) photodynamic therapy of human OVCAR-3 tumor xenografts. Photochem Photobiol 69: 236-241, 1999.

33. Guyon L, Farine MO, Lesage JC, Gevaert AM, Simonin S, Schmitt C, Collinet P and Mordon S: Photodynamic therapy of ovarian cancer peritoneal metastasis with hexaminolevulinate: A toxicity study. Photodiagnosis Photodyn Ther 11: 265-274, 2014. 